Feature Article

\title{
Mixed metal oxides from sucrose and cornstarch templated hydrotalcite-like LDHs as catalysts for ethyl biodiesel synthesis
}

\author{
Adonis Coelho, Olavo Micali Perrone, Eleni Gomes, Roberto Da-Silva, \\ João Claudio Thoméo, Mauricio Boscolo*
}

IBILCE/UNESP, Univ Estadual Paulista, Campus São Jose Rio Preto, Rua Cristóvão Colombo, $n^{\circ}$ 2265-CEP 15054-000, São Jose do Rio Preto, SP, Brazil

\section{A R T I C L E I N F O}

\section{Article history:}

Received 26 July 2016

Received in revised form

12 December 2016

Accepted 14 December 2016

Available online 15 December 2016

\section{Keywords:}

Bioenergy

Ethyl biodiesel

Heterogeneous catalysis

Hydrotalcites

Metal mixed oxides

\begin{abstract}
A B S T R A C T
Sucrose and cornstarch were used as organic templates in the synthesis of hydrotalcite-like layered double hydroxides (LDHs) prepared by the coprecipitation with partial replacement of $\mathrm{Mg}$ by $\mathrm{Zn}$, and $\mathrm{Al}$ by Fe. Non-template materials were taken as references. All LDHs were used as precursors of mixed metal oxides (MMOs) by calcination and applied as catalysts for ethyl biodiesel synthesis via transesterification reactions of soybean oil and ethanol. The LDHs were characterized by XRD, TG, FTIR-ATR and the respective MMOs by SEM, BET, basicity and acidity. Crystallographic data from templated LDHs showed lower crystallinity compared to the reference homologous materials, and it was observed that cornstarch decreases the average surface areas (from 173 to $94 \mathrm{~m}^{2} \mathrm{~g}^{-1}$ ) and the size of the crystallites (from 147 to $92 \AA$ ). FTIR spectra indicated carbohydrates were occluded inside the crystals. While this did not influence the number of acidic sites on the MMOs, it enhances the alkaline sites. Under the catalytic conditions of this experiment, cornstarch templated MMOs reach an average ethyl biodiesel conversion of $70 \%$ whereas those prepared with sucrose $45 \%$, and the homologous reference materials only $36 \%$. These results demonstrated the great potential of using carbohydrates as biotemplates in the preparation of heterogeneous catalysts for transesterification reactions.
\end{abstract}

(c) 2016 Elsevier B.V. All rights reserved.

\section{Introduction}

The production of biodiesel has been increasing every year due the demand for sustainable and cleaner fuels to replace fossil diesel $[1,2]$. Biodiesel is produced by transesterification of short chain alcohols with oils or fats. Triglyceride sources change from country to country and, in Brazil, mainly soybean oil and methanol are used due to the availability and low-cost of these raw-materials. However, methanol has high toxicity and, at present, originates mainly from fossil oil [3]. The use of bioethanol instead of methanol would take advantage of the existing agricultural industry and make this process more sustainable.

The use of $\mathrm{NaOH}$ or $\mathrm{KOH}$ as homogeneous transesterification catalysts generates large amounts of waste, mainly originating from the washing step [4] and this can be minimized by using heterogeneous catalysts which are easily separated from the final product

\footnotetext{
* Corresponding author.

E-mail addresses: adonis.don@hotmail.com (A. Coelho)

olavo_perrone@hotmail.com (O.M. Perrone), eleni@ibilce.unesp.br (E. Gomes), dasilva@ibilce.unesp.br (R. Da-Silva), thomeo@ibilce.unesp.br (J.C. Thoméo), boscolo@ibilce.unesp.br (M. Boscolo).
}

and can be reused [5]. With ethanol, the hygroscopicity of this substrate is also a negative issue with homogeneous alkaline catalysis leading to saponification.

Heterogeneous catalysts such as mixed metal oxides (MMOs) with high surface area and Lewis acid-base sites can easily be produced from the calcination of layered double hydroxides (LDHs) [6]. In addition, hydrotalcite-like materials have received significant attention from the environmental and economic point of view because they are made of Earth-abundant and non-toxic elements such as magnesium and aluminum.

Hydrotalcite is a natural $\mathrm{LDH}$ with general formula $\mathrm{Mg}_{6} \mathrm{Al}_{2}\left(\mathrm{CO}_{3}\right)(\mathrm{OH})_{16} \cdot 4 \mathrm{H}_{2} \mathrm{O}$ [7] and can be modified by changing the ratio of $\mathrm{M}^{2+} / \mathrm{M}^{3+}$ from 1 to 8 [8], or by partial substitution of $\mathrm{Mg}$ or $\mathrm{Al}$ for other metal ions $[9,10]$ keeping the same ratio $\mathrm{M}^{2+} / \mathrm{M}^{3+}$ and are good precursors of MMO catalysts after calcination.

Different strategies have been investigated to modulate the catalytic activity of these oxides, such as the introduction of organic molecules as templates during the LDH coprecipitation process [11], aiming to enhance the specific surface area or to change the ratio of Lewis acid/base sites. The interaction between organic templates and the lamellar materials can lead to significant changes on the morphology and particles size, in order to develop the cat- 
alytic and adsorbent properties. Some templated materials have already been studied for this purpose, such as bacterial cellulose [12], cationic starch [13], egg protein [14], liquid crystals [15], chitosan [16,17], pollen [18], rice starch [19,20], cyclodextrin [21] and even viruses for biotechnological applications [22].

The aim of this work was to synthesize materials with high transesterification catalytic activity by changing interatomic distances using two very inexpensive carbohydrates (cornstarch and sucrose) as templates for hydrotalcite-like materials. These LDHs were prepared by replacing $10 \%$ of the $\mathrm{Mg}^{2+}$ with $\mathrm{Zn}^{2+}$ and $10 \%$ of the $\mathrm{Al}^{3+}$ with $\mathrm{Fe}^{3+}$ in the synthesis of $3: 1 \mathrm{Mg}^{2+}: \mathrm{Al}^{3+}$ hydrotalcite precursors. The transesterification catalytic activities for ethyl-soybean oil biodiesel production were evaluated for MMOs prepared by calcining these materials and correlated with structural and chemical properties.

\section{Experimental}

\subsection{Synthesis of the catalysts}

Typical hydrotalcite preparation involved the coprecipitation at $\mathrm{pH} \sim 10$ of suitable amounts of metal nitrates $\left(\mathrm{Mg}\left(\mathrm{NO}_{3}\right)_{2} \cdot 6 \mathrm{H}_{2} \mathrm{O}\right.$ and $\left.\mathrm{Al}\left(\mathrm{NO}_{3}\right)_{3} \cdot 9 \mathrm{H}_{2} \mathrm{O}\right)$ with a $3: 1 \mathrm{Mg}^{2+}: \mathrm{Al}^{3+}$ molar ratio [8]. The precipitation was carried out by slow dropwise addition of an aqueous metal nitrates solution containing $0.45 \mathrm{~mol}$ of $\mathrm{Mg}^{2+}$ and $0.15 \mathrm{~mol}$ of $\mathrm{Al}^{3+}$ into a well-stirred beaker containing aqueous $\mathrm{Na}_{2} \mathrm{CO}_{3}$ $\left(0.075 \mathrm{~mol} \mathrm{~L}^{-1}\right)$. The resulting mixture was kept under agitation at $60^{\circ} \mathrm{C}$ for 3 days in order for the crystals to grow and mature. The precipitate was isolated by vacuum filtration and washed with distilled water to remove soluble components until the washings reached a neutral $\mathrm{pH}$. The collected solid was then dried at $100^{\circ} \mathrm{C}$ for $12 \mathrm{~h}$.

Hydrotalcite-like materials were made by replacing $10 \%$ of $\mathrm{Mg}^{2+}$ ions by $\mathrm{Zn}^{2+}(\mathrm{MgZnAl})$ or $10 \%$ of $\mathrm{Al}^{3+}$ ions by $\mathrm{Fe}^{3+}(\mathrm{MgAlFe})$ or by making both substitutions (MgZnAlFe) in the nitrates solution before the precipitation process. In these cases, $\mathrm{Zn}\left(\mathrm{NO}_{3}\right)_{2} \cdot 6 \mathrm{H}_{2} \mathrm{O}$ and $\mathrm{Fe}\left(\mathrm{NO}_{3}\right)_{3} \cdot 9 \mathrm{H}_{2} \mathrm{O}$ were used. Templated LDHs were prepared by dissolving $20 \mathrm{~g}$ of sucrose or $5.0 \mathrm{~g}$ of cornstarch pregelatinized for $10 \mathrm{~min}$ at $80^{\circ} \mathrm{C}$ (identified as SU and ST, respectively and RE refers to non-templated reference solids) into the sodium carbonate solution and performing the same precipitation process as described previously.

The MMO catalysts were obtained by calcination of the resulting LDHs in air at $450^{\circ} \mathrm{C}$ for $4 \mathrm{~h}$, followed by trituration in a mortar and sieving through 150 mesh.

\subsection{Characterization of materials}

Powder X-ray diffraction (XRD) patterns of LDHs were obtained on a Model 300 MiniFlex Rigaku ${ }^{\circledR}$ diffractometer using $\mathrm{CuK} \alpha$ radiation $(\lambda=1.54 \AA)$ in an angular range of $5-70^{\circ}$ at $2 \theta \mathrm{min}^{-1}$ and $25^{\circ} \mathrm{C}$. The Miller indices of the planes (003) and (110) were used to calculate the corresponding lattice parameters and the crystallite sizes were calculated from the diffraction line at $2 \theta=62.5^{\circ}$, using the Scherrer Equation [23-25].

Thermal decomposition was studied using a thermogravimetric balance TGA 4000-PerkinElmer ${ }^{\circledR}$ with approximately $10 \mathrm{mg}$ of LDH sample under $\mathrm{N}_{2}$ atmosphere $\left(20 \mathrm{~mL} \mathrm{~min}^{-1}\right)$. Basicity and acidity were determined by gain of mass at $50{ }^{\circ} \mathrm{C}$ inside the same thermogravimetric balance with approximately $10 \mathrm{mg}$ of MMO samples. Basicity was determined by $\mathrm{CO}_{2}$ adsorption [26,27] and acidity by $n$-butylamine adsorption [28]. Both properties were expressed as the number of moles per gram of MMO.

The specific surface area was achieved by using the conventional BET nitrogen adsorption method in a Gemini model 2390
VII analyzer (Micromeritics ${ }^{\circledR}$ ) [29]. MMO samples of approximately $0.2 \mathrm{~g}$ were preheated at $110^{\circ} \mathrm{C}$ for $1 \mathrm{~h}$ in a nitrogen atmosphere to remove any traces of moisture that might interfere with the results. The vibrational spectra in the range $4000-400 \mathrm{~cm}^{-1}$ were collected using an ATR-FTIR Spectrum Two spectrophotometer $\left(\right.$ PerkinElmer $^{\circledR}$ ).

To evaluate the catalyst leaching, metal analysis was performed on the soybean oil and reaction products which were calcined at $650^{\circ} \mathrm{C}$ and the ash dissolved in $6 \mathrm{~mL}$ of nitric acid $(20 \% \mathrm{v} / \mathrm{v})$ by $12 \mathrm{~h}$ and after diluted to $25 \mathrm{~mL}$ for analysis. The measurements were recorded in a Varian AA240FS flame spectrophotometer by means of atomic emission for $\mathrm{Na}$ and atomic absorption for $\mathrm{Fe}, \mathrm{Mg}, \mathrm{Zn}$ and $\mathrm{Al}$, following the procedures indicated for each element in the instrument manual, adjusting wavelength, flame composition, slit width, lamp current and concentration range.

\subsection{Biodiesel production and quantification}

Transesterifications of commercial soybean oil with anhydrous ethyl alcohol were carried out in duplicate as batch reactions in closed vessels at $120^{\circ} \mathrm{C}$ with self-generated pressure under constant stirring ( $450 \mathrm{rpm}$ for $12 \mathrm{~h}$ ). The ethanol:oil molar ratio was 20:1 with $20 \%(\mathrm{~m} / \mathrm{m})$ of the MMO to oil. Excess ethanol was removed by vacuum distillation and the catalyst separated from the liquid by centrifugation ( $10 \mathrm{~min}$ at $10 \mathrm{Krpm})$.

For the biodiesel chromatographic quantification, a one microliter aliquot of each product was appropriately diluted in hexane and injected into a gas chromatograph model Clarus 480 PerkinElmer $^{\circledR}$ with a flame ionization detector (FID) coupled to a capillary column Agilent ${ }^{\circledR} \mathrm{J} \& W$ Biodiesel EN 14103 Analysis GC Column ( $30 \mathrm{~m}$ length, $0.32 \mathrm{~mm}$ diameter, $0.25 \mu \mathrm{m}$ film thickness) using nitrogen as the carrier gas $\left(1.0 \mathrm{~mL} \mathrm{~min}^{-1}\right)$. The temperature of the column oven was programed from 60 to $200^{\circ} \mathrm{C}\left(10^{\circ} \mathrm{C} \mathrm{min}^{-1}\right)$ with a subsequent increase to $240^{\circ} \mathrm{C}\left(5^{\circ} \mathrm{C} \mathrm{min}-1\right)$. The injector and detector blocks were kept at $250^{\circ} \mathrm{C}$. Quantification was based on calibration curves using the ethyl esters (linoleate, linolenate, oleate, palmitate and stearate) as analytical standards and methyl heptadecanoate was used as an internal standard, all from SigmaAldrich $^{\circledR}$. Synthesis yield was defined as the total mass of esters obtained in relation to the expected theoretical mass [30].

\section{Results and discussion}

\subsection{Characterization of materials}

The powder XRD patterns exhibit a typical single phase structure for all the prepared LDHs, indicating the incorporation of iron and zinc ions into the lattice (Fig. 1) with characteristic basal peaks classified as a hexagonal crystal system with rhombohedral symmetry (3R) [31]. Reflections for the Miller planes (003), (006), (110) and (113), and broad and asymmetric peaks for (012), (015) and (018) can be seen. The diffraction lines appearing at $2 \theta=30^{\circ}$, identified with an asterisk in the LDHs templated with sucrose and cornstarch, correspond to imperfect nitrate elimination from these materials. This fact indicates that the incorporation of saccharides affects the ion diffusion outside the crystal structure, since these peaks are not observed in homologous non-templated materials. In general, diffraction peaks of the ST-LDHs are less intense and narrow, revealing lower crystallinity than the others.

Lattice parameters are shown in Table 1 and, interestingly, it was observed that the size of the unit cell (parameter a) has not changed with the replacement of metals separately, and their changes are a few thousandths of an Angstrom, whereas for the combined inclusion of $\mathrm{Zn}$ and Fe there was an increase of $0.061 \AA$. This result could indicate that there is a synergistic effect of the substituent ions and 

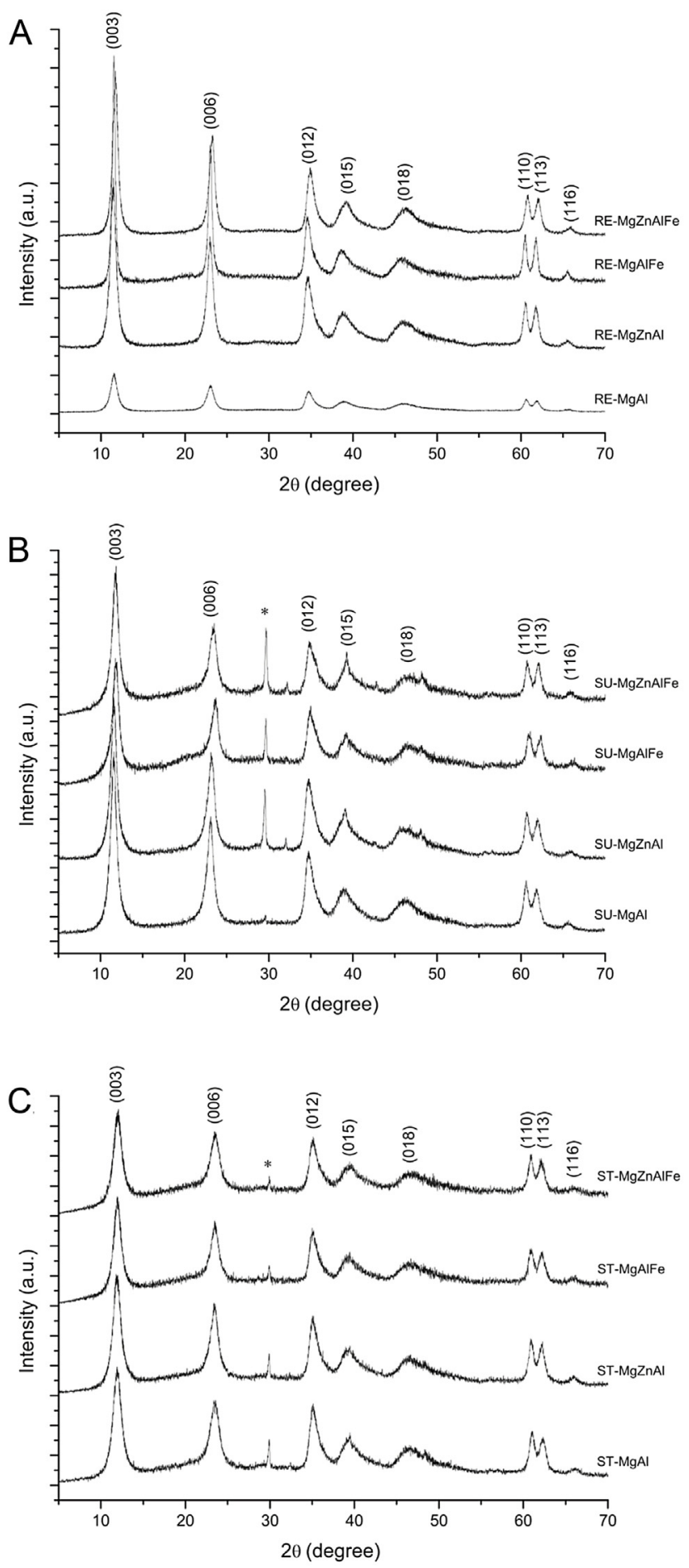

Fig. 1. Powder XRD pattern diffractions of LDHs. (A) non-templated references -RE; (B) sucrose templated -SU and (C) cornstarch templated-ST.

not only an effect of the substituents ionic radius in brucite lamellae [32].

SU- and ST-LDHs showed an increase in the size of the unit cell compared to their respective homologous reference materials and the greatest variation was observed between $\mathrm{MgAl}$ and SU-MgAl, ranging from 3.00 to $3.06 \AA$.

The interlayer distance depends mainly on the size of the intercalated anion, degree of hydration and electrostatic forces [31]. The interlayer distance of RE-MgZnAlFe was reduced in its homologous cornstarch templated ST-MgZnAlFe from 22.9 to $22.0 \AA ̊$. It was
Table 1

LDHs lattice parameters.

\begin{tabular}{llll}
\hline \multirow{2}{*}{ Material } & \multicolumn{2}{l}{ Crystallographic parameters } \\
\cline { 2 - 4 } & $a(\AA)$ & $c(\AA)$ & $D(\AA)$ \\
\hline RE-MgAl & 3.00 & 22.9 & 102.5 \\
RE-MgAlFe & 3.00 & 22.9 & 181.3 \\
RE-MgZnAl & 3.00 & 22.9 & 159.7 \\
RE-MgZnAlFe & 3.06 & 22.9 & 145.7 \\
SU-MgAl & 3.06 & 22.8 & 76.87 \\
SU-MgAlFe & 3.04 & 22.4 & 103.9 \\
SU-MgZnAl & 3.05 & 22.7 & 102.7 \\
SU-MgZnAlFe & 3.05 & 22.5 & 103.9 \\
ST-MgAl & 3.04 & 22.1 & 86.33 \\
ST-MgAlFe & 3.04 & 22.0 & 96.00 \\
ST-MgZnAl & 3.04 & 22.0 & 94.50 \\
ST-MgZnAlFe & 3.04 & 22.0 & 90.40 \\
\hline
\end{tabular}

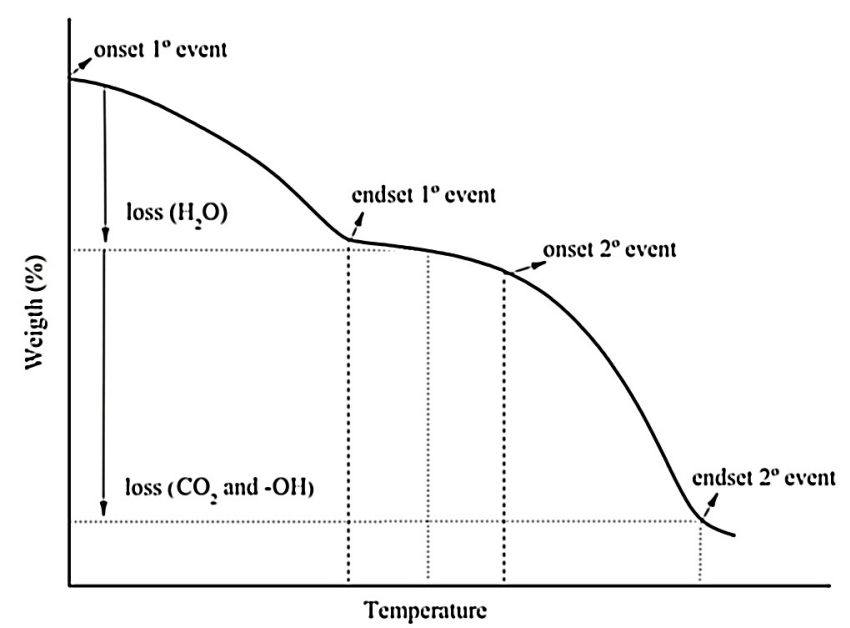

Fig. 2. General LDH decomposition thermogram pointing out the onset and endset events.

expected that this parameter would have higher values for templated materials when compared to the reference materials but in this study, the opposite was observed. In a further bibliographic search, it was found that Sommer et al. [14] have found similar results by using protein as a biotemplate for the preparation of LDHs. It is not yet clear how these saccharides interfere in the formation process of the LDHs crystalline structures but it is certainly not by intercalation in the interlayer space.

It is very clear that carbohydrates affect the crystal growth but there is no evidence that the saccharide chain size is a keyfactor for that. From all LDHs studied in this work, RE-MgAlFe showed the biggest crystallite (181.3 $\AA$ ), and SU-MgAl the smallest one $(76.9 \AA)$. For homologous materials, the largest variation was observed between RE-MgAlFe (181.3 $\AA$ ) and ST-MgAlFe (96.0 $)$, a reduction of about $52 \%$.

Fig. 2 shows the thermal decomposition events for typical LDHs and the onset and end set values change for each material. The first event occurs in the range $100-250^{\circ} \mathrm{C}$ with an average mass loss of $12 \%$ due to the physically adsorbed water removal [33]. The second event occurs in the range $250-550^{\circ} \mathrm{C}$ with an average mass loss of $28 \%$ due to the decarbonation followed by the dehydroxylation of the lamellae [34]. Above $450^{\circ} \mathrm{C}$, masses were measured at about $60 \%$ of the initial mass, the result of the collapse of the lamellar structure and formation of mixed oxides of the spinel type $\left(\mathrm{MgAl}_{2} \mathrm{O}_{4}\right)$ as residue [35]. The organic fraction was converted to $\mathrm{CO} 2$ and $\mathrm{H} 2 \mathrm{O}$ and the minerals remained in the catalyst in very small quantities. The FTIR spectra indicated no residual carbon in 
the oxides and XRD data showed no difference between the templated and non-templated materials (Figs. S1 and S2).

In Table 2, the loss of mass of the LDHs during calcination and the respective MMOs surface areas, basicity and acidity is summarized. According to Shumaker et al. [36], MMOs should have a higher specific surface area than LDHs due to the formation of micro and mesopores by the elimination of steam and $\mathrm{CO}_{2}[23,37]$. In general, the MMO derivatives from both templated saccharide HDLs showed smaller surface areas than their respective homologous references, except for SU-MgAlFe. The smallest surface area determined was for the MMO-ST-MgAl $\left(62 \mathrm{~m}^{2} \mathrm{~g}^{-1}\right)$, and the largest one for MMO-RE-MgZnAl $\left(208 \mathrm{~m}^{2} \mathrm{~g}^{-1}\right)$.

In fact, there is no proven relationship between the increase in surface area of the oxide and the catalytic activity. Nowicki et al. [38] in their study of LDH with added Zr achieved the best catalytic activity with an oxide containing $\mathrm{Zr}$ and a surface area four times less than that of the reference. Cross et al. [39] investigated different forms of LDH calcination and got higher catalytic activity with oxides with smaller surface areas. Wang et al. [40] found that the increase of concentration of $\mathrm{Mg}$ in LDHs reduced the surface area due to the formation of $\mathrm{Mg}^{2+}-\mathrm{O}^{2-}$ and $\mathrm{Al}^{3+}-\mathrm{O}^{2-}$ pairs and increased the catalytic activity.

There is a correlation between the average crystallite size and the mass loss during the second thermal degradation event. The average mass loss of the reference LDHs was 23\%, around 5-9\% lower than the respective homologous SU-MMO (27.5\%) and STMMOs (32.5\%), indicating that, during the washing process, these saccharides were not entirely removed, as pointed out by Ramimoghadam et al. [19]. Since the crystallographic data did not indicate the carbohydrates were in the interlayer lamellae, it suggests that they are occluded inside the crystals.

Regarding the acid-base properties, the SU-MMOs showed the highest average basicity $\left(0.53 \mathrm{mmol}\right.$ of $\mathrm{CO}_{2}$ adsorbed per gram of oxide) followed by the ST-MMOs $\left(0.47 \mathrm{mmol} \mathrm{CO}_{2} \mathrm{~g}^{-1}\right)$ and third was the RE-MMOs $\left(0.43 \mathrm{mmol} \mathrm{CO}_{2} \mathrm{~g}^{-1}\right)$. By templating LDHs with sucrose and cornstarch, the basicity of the MMOs was enhanced except for the MgAl homologous series, in which MMO-SU-MgAl decreased by $0.11 \mathrm{mmol} \mathrm{CO}_{2} \mathrm{~g}^{-1}$ and MMO-ST-MgAl decreased by $0.26 \mathrm{mmol} \mathrm{CO}_{2} \mathrm{~g}^{-1}$ when compared to MMO-RE-MgAl.

The data on XRD of the synthesized oxides showed that part of the magnesium was converted into periclase $(\mathrm{MgO})$, a very alkaline material, and the basicity of the catalysts is proportional to the amount of magnesium Wang et al. [48], and so the replacement of $\mathrm{Mg}$ by $\mathrm{Zn}$ reduced the basicity, as expected. In the same way, the partial replacement of $\mathrm{Al}^{3+}$ by $\mathrm{Fe}^{3+}$ which is a weaker Lewis acid, reduces the $\mathrm{M}^{3+}-\mathrm{O}^{2-}$ dipole moment, leading to changes in the acid-basic catalytic properties of the materials which was part of this study.

However in templated materials containing $\mathrm{Zn}$ and Fe the opposite was seen, i.e., there was an increase in the number of basic catalytic sites. There are several possible factors which may be related to this effect, such as the structural modifications seen in the precursor $(i)$ increase in the size of the unit cell and (ii) decrease in the interlayer distance, that influence the surface area of the MMO.

By comparing the average specific surface areas of the reference materials $\left(173 \mathrm{~m}^{2} \mathrm{~g}^{-1}\right)$ to those of sucrose templated oxides $\left(125 \mathrm{~m}^{2} \mathrm{~g}^{-1}\right)$ and cornstarch templated MMOs $\left(94 \mathrm{~m}^{2} \mathrm{~g}^{-1}\right)$ with their $\mathrm{CO}_{2}$ adsorption capacities, one can see there is not a good correlation between these characteristics and no differences were found in the acidity values for the $n$-butylamine adsorbed. According to Yavuzet al. [26], the $\mathrm{CO}_{2}$ adsorption capacity is more related to the chemical characteristics of the material than its specific surface area or the volume of its pores. The following variables (temperature, $\mathrm{pH}$ of the solution during precipitation, and the maturation period of the precipitate) can have a strong influence on the MMO basicity [41], but these were not investigated in this study.
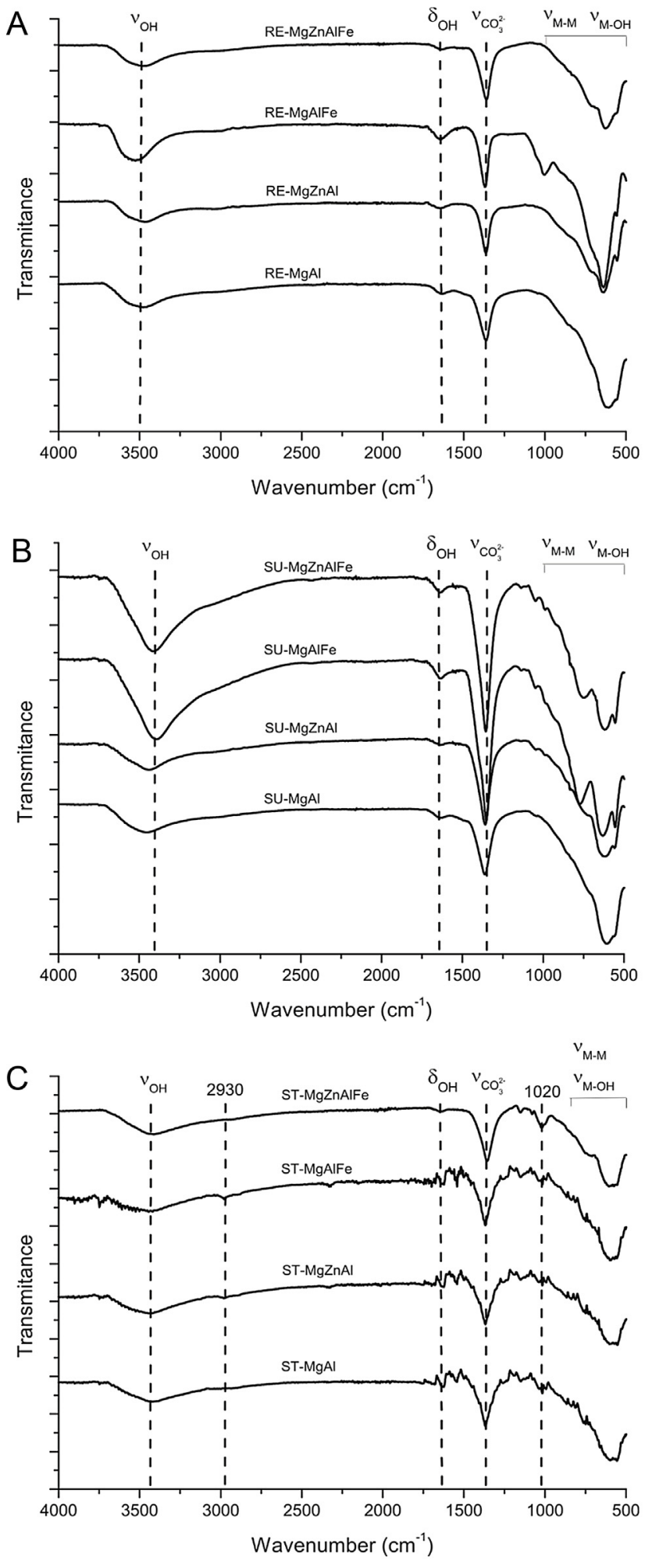

Fig. 3. ATR-FTIR spectra of the synthesized LDHs. (A) non-templated (reference); (B) sucrose templated, and (C) cornstarch templated.

In addition, according to Gabriëls et al. [42], there are $\mathrm{O}^{2-}$ ions in the oxides with low structural coordination, which are BrønstedLowry strong base forming alkoxides during the reaction, helping the nucleophilic attack of the carbonyl carbon of the glyceride to form the tetrahedral intermediate adduct in the transesterification reaction. 
Table 2

LDH and MMO physical-chemical characterization: TGA mass loss, BET specific surface area, basicity and acidity.

\begin{tabular}{|c|c|c|c|c|c|c|}
\hline \multirow[t]{2}{*}{ Composition } & \multicolumn{3}{|l|}{ LDH mass loss } & \multirow{2}{*}{$\begin{array}{l}\text { MMO } \\
\mathrm{S}_{\text {BET }}\left(\mathrm{m}^{2} \mathrm{~g}^{-1}\right)\end{array}$} & \multirow[t]{2}{*}{ MMO Basicity } & \multirow[t]{2}{*}{ MMO Acidity } \\
\hline & 1st event (\%) & 2nd event (\%) & Total (\%) & & & \\
\hline RE-MgAl & 11.9 & 23.4 & 35.3 & $178 \pm 2$ & 0.57 & 0.09 \\
\hline RE-MgAlFe & 12.2 & 21.8 & 34.0 & $153 \pm 1$ & 0.41 & 0.06 \\
\hline RE-MgZnAl & 14.3 & 24.8 & 39.1 & $208 \pm 3$ & 0.45 & 0.09 \\
\hline RE-MgZnAlFe & 11.1 & 21.6 & 32.7 & $151 \pm 1$ & 0.29 & 0.07 \\
\hline SU-MgAl & 12.8 & 24.6 & 37.4 & $146 \pm 1$ & 0.46 & 0.10 \\
\hline SU-MgAlFe & 14.0 & 29.2 & 43.2 & $156 \pm 1$ & 0.59 & 0.11 \\
\hline SU-MgZnAl & 13.6 & 28.0 & 41.6 & $113 \pm 1$ & 0.59 & 0.12 \\
\hline SU-MgZnAlFe & 11.5 & 28.3 & 39.8 & $85 \pm 1$ & 0.48 & 0.08 \\
\hline ST-MgAl & 11.2 & 33.9 & 45.1 & $62 \pm 1$ & 0.31 & 0.09 \\
\hline ST-MgAlFe & 12.8 & 31.6 & 44.4 & $102 \pm 1$ & 0.60 & 0.06 \\
\hline ST-MgZnAl & 10.7 & 33.7 & 44.4 & $85 \pm 1$ & 0.58 & 0.09 \\
\hline ST-MgZnAlFe & 12.8 & 30.8 & 43.6 & $127 \pm 1$ & 0.40 & 0.10 \\
\hline
\end{tabular}

a $\mathrm{mmol}$ of $\mathrm{CO}_{2}$ adsorbed per gram of MMO.

b mmol of $n$-butylamine adsorbed per gram of MMO.

Vibrational spectra for all LDHS are shown in Fig. 3, and they are similar to those presented in previous studies [35]. The strong and broad absorption band between 3500 and $3400 \mathrm{~cm}^{-1}$ is due to the stretching mode of structural $-\mathrm{OH}$ groups $\left(\nu_{\mathrm{OH}}\right)$ in the metal hydroxide layer and the interlayer water molecules [32,43]. The weak absorption around $1630 \mathrm{~cm}^{-1}$ is attributed to the angular deformation of the $\mathrm{OH}$ groups of water molecules $\left(\delta_{\mathrm{OH}}\right)$. The intensity of these two bands depends on the type of anion and amount of interlayer water. In general, for the materials prepared in this work, it was observed that the non-templated LDHs exhibit more intense hydroxyl bands than ST-LDHs but less intense than those of SU-LDHs.

The SU-MMOs had an average specific surface area of $125 \mathrm{~m}^{2} \mathrm{~g}^{-1}$ and the ST-MMOs had $94 \mathrm{~m}^{2} \mathrm{~g}^{-1}$, while the RE-MMOs had an area of $173 \mathrm{~m}^{2} \mathrm{~g}^{-1}$. The discrepancy in the surface areas in the sucrose and cornstarch templated MMOs can be explained by the presence of carbonate ions and organic materials. The intense band at $1370 \mathrm{~cm}^{-1}$ is related to the $\mathrm{C}=0$ asymmetric stretch mode $(\nu 3)$ of the interleaved carbonate ions, and the shoulder at $1380 \mathrm{~cm}^{-1}$ to the asymmetrical stretching of the nitrate ions $[33,44]$. In the low wavenumber region, the absorption around $540-570 \mathrm{~cm}^{-1}$ can be attributed to the vibration of the carbonate-water units or attributed to network vibration modes O-M-O, M-O-M and $\mathrm{M}-\mathrm{OH}$ $[45,46]$ or both.

In Fig. 3C, the absorption at $1020 \mathrm{~cm}^{-1}$ corresponding to the $\mathrm{C}-\mathrm{O}$ bond stretching vibration of the $\mathrm{C}-\mathrm{O}-\mathrm{C}$ group in the anhydroglucose ring of cornstarch [13,47] and the absorption at $2930 \mathrm{~cm}^{-1}$ corresponding to the $\mathrm{C}-\mathrm{H}$ bond stretching indicating that the cornstarch is in fact occluded in the LDH crystal.

The morphological characteristics of all templated MgZnAlFe homologous LDHs and their respective MMOs are shown in Fig. 4. In general, the solids have irregular sizes on which are deposited spherical, plate-like and needle-like nanoparticles.

Typical rosette morphology is seen in Fig. 4(A) and (B) and a possible explanation for that is based on the isoelectric point of $3 \mathrm{Mg} / \mathrm{Al}$ LDH being at $\mathrm{pH} 10$ and initially the formation of nanoparticles of $\mathrm{Al}(\mathrm{OH})_{3}$ and $\mathrm{Mg}(\mathrm{OH})_{2}$ occurs, which are immediately converted into hydrotalcites. Because the primary surface of $\mathrm{Mg}_{3}-\mathrm{Al}-\mathrm{CO}_{3}$ is electrically neutral, its growth is relatively slow and occurs in the direction of the crystallographic plane [001], which has the lowest charge density on the surface, favoring the growth with rosette morphology [44].

In the templated materials, the morphological characteristics are not so evident, although they can be seen with lesser intensity in Fig. 4(E) (ST-LDH). So, logically, the carbohydrates present in the precipitation probably interfere with the growth of crystal-
Table 3

Ethyl biodiesel yields with different MMOs as catalysts.

\begin{tabular}{llll}
\hline Material & \multicolumn{2}{l}{ Yield (\%) } \\
\cline { 2 - 4 } & RE & SU & ST \\
\hline MgAl & $43 \pm 8$ & $28 \pm 2$ & $73 \pm 5$ \\
MgAlFe & $17 \pm 2$ & $50 \pm 4$ & $64 \pm 3$ \\
MgZnAl & $22 \pm 1$ & $51 \pm 4$ & $59 \pm 5$ \\
MgZnAlFe & $61 \pm 5$ & $50 \pm 3$ & $85 \pm 3$ \\
\hline
\end{tabular}

(RE) non-templated reference materials; (SU) Sucrose templated materials; (ST) cornstarch templated materials.

lographic planes and, thus, the catalytic properties of the materials as shown by the structural alterations seen using XRD.

\subsection{Catalytic biodiesel production}

Table 3 shows the ethyl biodiesel yield for the different MMO materials described above. The conditions are described in the Experimental Section, but briefly these were batch reactions in closed vessels at $120^{\circ} \mathrm{C}$ with self-generated pressure under constant stirring. Products were analyzed in duplicate by GC-FID.

The ST-MMOs promoted an average general conversion of ethyl biodiesel about 100\% higher than the reference materials $(70 \%$ versus $36 \%$ ), while the average of the SU-MMOs was $45 \%$, which is $25 \%$ more than the RE-MMOs over the $12 \mathrm{~h}$ course of the catalysis runs.

The best biodiesel conversion (85\%) was obtained with MMOST-MgZnAlFe and the worst one (17\%) with MMO-RE-MgAlFe. But this latter homologous material showed the greatest variations in catalytic activity when templated to sucrose (290\%) and to cornstarch (376\%) revealing the strong capacity of these carbohydrates to promote structural changes and enhance the transesterification activity. However, with MMO-SU-MgAl and MMO-SU-MgZnAlFe, the catalytic activity was reduced from 42 to $28 \%$ and from 61 to $50 \%$, respectively.

The chemical and structural characteristics observed in the oxides and their respective LDH precursors discussed above are important factors to understanding the catalytic power for ethyl biodiesel conversion. It is known that basic/acid site density and specific surface area are important factors for the catalytic transesterification yield; however our data did not show any correlation. Among the different characteristics of the materials studied, an inverse correlation was found between the catalytic power of the oxides and the interlamellar distances of their respective $\mathrm{LDH}$ precursors as shown in Fig. 5. Probably smaller interlamellar distances contribute to generate ethyl alkoxide closer to the glyceride 


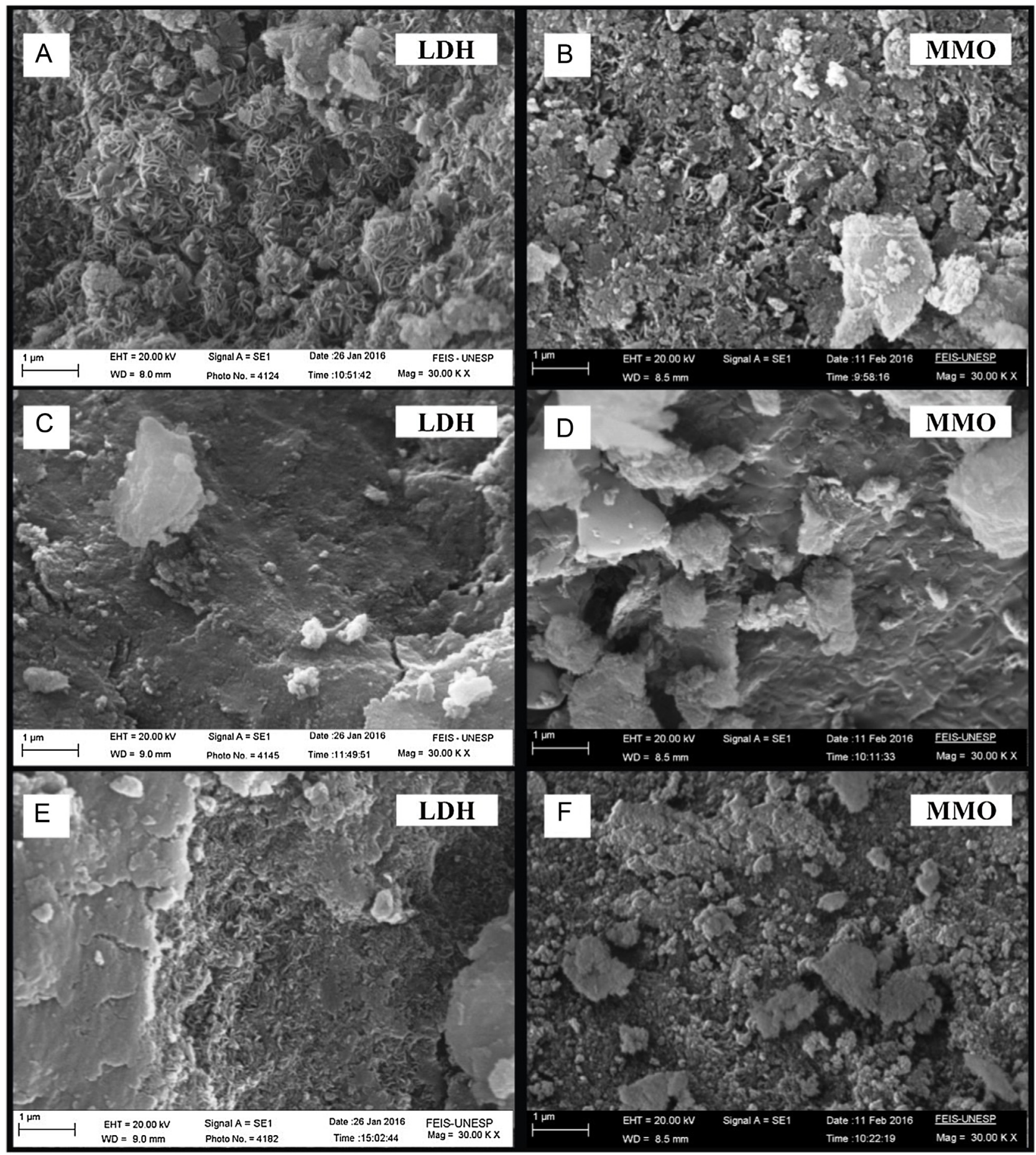

Fig. 4. SEM micrographs of MgZnAIFe LDHs and their respective oxides. (A) Non-templated; (B) Sucrose templated; (C) Starch templated.

carbonyl group making the nucleophilic attack to form the tetrahedral intermediate adduct easier. In this way, it is clear that starch biotemplating significantly improves the catalytic capacity of the oxides and this procedure cannot be ignored in the development of new catalysts.

\subsection{Catalysts regeneration}

To know the reuse capacity and, also, the stability of the catalysts, two materials (MMO-RE-MgAl and MMO-ST-MgZnAlFe) were submitted to three reaction cycles. In the end of each cycle, the catalysts were separated from the reaction products by centrifugation at $6000 \mathrm{rpm}$ for $10 \mathrm{~min}$, washed with acetone, dried, recalcinated at $450^{\circ} \mathrm{C}$ to be reused in the same conditions and the results are shown in Fig. 6.

Both materials had catalytic ability reduced by about $13 \%$ in the 2 st reaction cycle. In the 3rd cycle, the yield of the MMO-STMgZnAlFe material was reduced by $5 \%$ compared to the previous cycle, but with overlap between the experimental errors, while the 


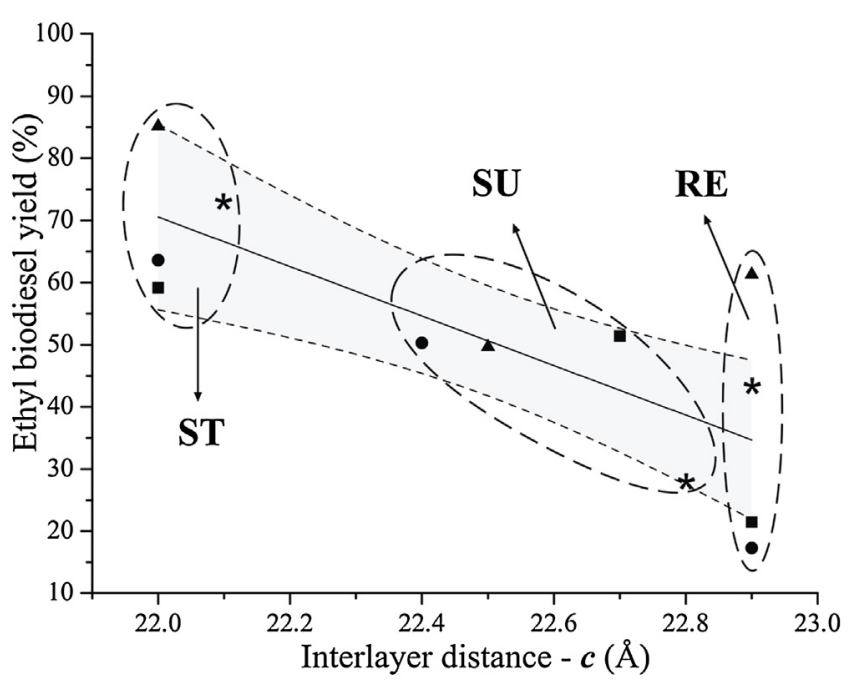

Fig. 5. The correlation between the catalytic potential of mixed oxides and the interlamellar distance of the LDHs precursors (the crystallographic parameter $c$ ). The shaded area shows the $95 \%$ confidence interval. (RE) non-templated reference materials; (SU) Sucrose templated materials; (ST) cornstarch templated materials;

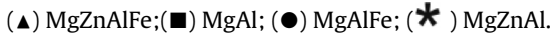

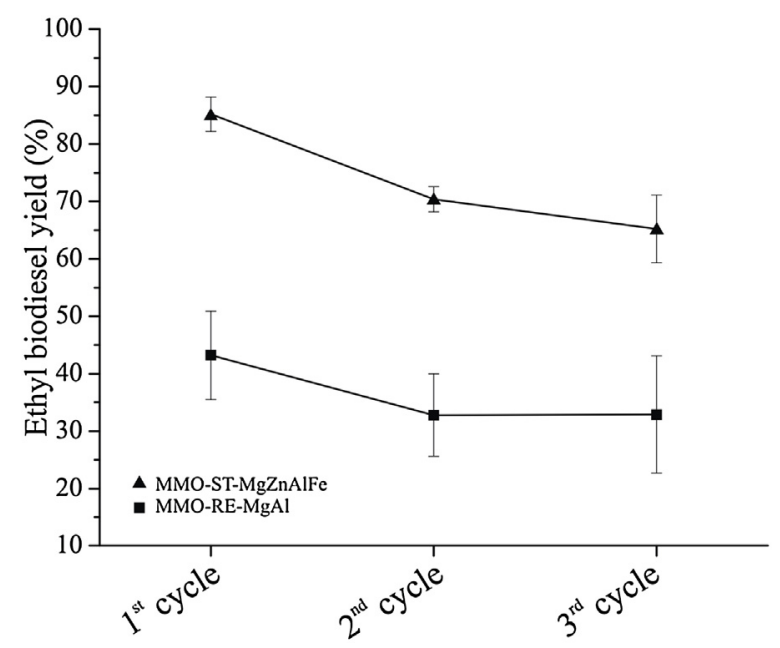

Fig. 6. Ethyl biodiesel yield after successive cycles of reaction.

MMO-RE-MgAl reference material essentially had no further loss of catalytic activity.

Oxide catalysts are bulk type materials and the composition of the interior oxides is the same as on the surface. In this way, a small part of its atoms effectively participates in the catalytic action. The sodium content measured in soybean oil before the reaction was $23.4 \pm 0.3 \mathrm{mg} \mathrm{kg}^{-1}$. After the 1 st reaction cycle, the sodium content in the product of transesterification reaction was $23.8 \pm 0.5 \mathrm{mg} \mathrm{kg}^{-1}$, this data shown that leaching of $\mathrm{Na}^{+}$from the catalyst does not occur under the reaction conditions and hence it does not contribute to the catalytic activity.

\section{Conclusions}

Hydrotalcite-like LDHs were successfully synthesized using the coprecipitation method, using sucrose and cornstarch as biotemplates and replacing $10 \%$ of $\mathrm{Mg}$ and $\mathrm{Al}$ by $\mathrm{Zn}$ and $\mathrm{Fe}$, respectively, as precursors for the respective oxides. XRD data revealed crystalline diffraction peak characteristics for a single phase LDH. The use of carbohydrates as biotemplates resulted in a reduction in the aver- age surface area as well as a significant decrease in the crystallite size in comparison to the homologous non-templated materials.

In the catalytic transesterification tests with soybean oil and ethanol, MMOs derived from cornstarch templated LDHs showed good catalytic capacity with an average increase of about $100 \%$ compared to the average for the reference materials. The best catalytic conversion (85\%) was obtained with MMO-ST-MgZnAlFe.

The inclusion of zinc and iron and the biotemplating procedure increased the basicity of the catalysts, without altering the acidic properties, which can be attributed to better exposure to oxygen atoms on the surface of these materials favoring the formation of ethoxides and consequently intensifying nucleophilic attack on the carbonyl glyceride.

\section{Acknowledgements}

The authors want to thank the Brazilian National Council for Scientific and Technological Development-CNPq (process 405620/2013-6) for financial support and scholarship grants, to the São Paulo State Research Foundation-FAPESP (processes 2013/23886-4; 2015/22954-1; 2015/11588-4) and to Isabela C. Constantino for her help with the metal analysis.

\section{Appendix A. Supplementary data}

Supplementary data associated with this article can be found, in the online version, at http://dx.doi.org/10.1016/j.apcata.2016.12. 012.

\section{References}

[1] A.F. Lee, K. Wilson, Catal. Today. 242 (2015) 3-18.

[2] A.A. Refaat, Int. J. Environ. Sci. Technol. 8 (2011) 203-221.

[3] U. Schuchardt, R. Sercheli, R.M. Vargas, Chem. Soc. 9 (1998) 199-210.

[4] F. Ma, M.A. Hanna, Bioresour. Technol. 70 (1999) 1-15.

[5] A. Corma, S.B.A. Hamid, S. Iborra, A. Velty, J. Catal. 234 (2005) 340-347.

[6] M.E. Borges, L. Díaz, Renew. Sustain. Energy Rev. 16 (2012) 2839-2849.

[7] Z.P. Xu, J. Zhang, M.O. Adebajo, H. Zhang, C. Zhou, Appl. Clay Sci. 53 (2011) $139-150$.

[8] E.L. Crepaldi, J.B. Valim, Quim. Nova 21 (1998) 300-311.

[9] G. Lourinho, P. Brito, Rev. Environ. Sci. Biotechnol. 14 (2015) 287-316.

[10] G.S. Macala, A.W. Robertson, C.L. Johnson, Z.B. Day, R.S. Lewis, M.G. White, A.V. Iretskii, P.C. Ford, Catal. Lett. 122 (2008) 205-209.

[11] H. Zhou, T. Fan, D. Zhang, ChemSusChem 4 (2011) 1344-1387.

[12] G.F. Perotti, H.S. Barud, S.J.L. Ribeiro, V.R.L. Constantino, J. Braz. Chem. Soc. 25 (2014) 1647-1655.

[13] S. Pal, D. Mal, R.P. Singh, Carbohydr. Polym. 59 (2005) 417-423.

[14] A.E. Sommer, G. Fetter, P. Bosch, O. Novelo, Adv. Technol. 22 (2011) 2638-2642.

[15] J.K. Zhao, Y.F. Xie, J. Xu, W.G. Hou, Acta Phys. Chim. Sin. 31 (2015) 1199-1206

[16] S.K. Janardhanan, I. Ramasamy, B.U. Nair, Transition Met. Chem. 33 (2008) 127-131.

[17] M. Nidhin, I. Ramasamy, S.K. Janardhanan, B.U. Nair, Bull. Mater. Sci. 31 (2008) 93-96.

[18] S.R. Hall, H. Bolger, S. Mann, Chem. Commun. 44 (2003) 2784-2785.

[19] D. Ramimoghadam, M.Z.B. Hussein, Y.H. Taufiq-Yap, Chem. Cent. J. 7 (2013) $1-10$.

[20] M. Li, J. Ping, S. Ruiqin, C. Yuan, X. Qinhua, Chin. J. Catal. 30 (2009) 631-636.

[21] A. Ciobanu, S. Ruellan, I. Mallard, D. Landy, C. Gennequin, S. Siffert, S. Fourmentin, J. Inclusion Phenom. Macrocycl. Chem. 75 (2013) 333-339.

[22] C. Fowler, W. Shenton, G. Stubbs, S. Mann, J. Adv. Mater. 13 (2001) 1266-1269.

[23] F. Cavani, F. Trifirò, A. Vaccari, Catal. Today 11 (1991) 173-301.

[24] M. Hájek, P. Kutalek, L. Smolakova, I. Troppova, L. Capek, D. Kubicka, J. Kocik, D.N. Thanh, Chem. Eng. J. 263 (2015) 160-167.

[25] J. Pérez-Ramírez, G. Mul, A.J. Moulijn, Vib. Spectrosc. 27 (2001) 75-88.

[26] C.T. Yavuz, B.D. Shinall, A.V. Iretskii, M.G. White, T. Golden, M. Atilhan, P.C. Ford, G.D. Stucky, Chem. Mater. 21 (2009) 3473-3475.

[27] Z.S. Liu, Y.H. Peng, C.Y. Huang, M.J. Hung, Acta 602 (2015) 8-14.

[28] A.O.S. Silva, M.J.B. Souza, M.F.B. Aquino, V.J. Fernandes Jr., A.S. Araújo, J. Therm. Anal. Calorim. 76 (2004) 783-791.

[29] E.P. Barrett, L.G. Joyner, P.P. Halenda, JACS 73 (1951) 373-380.

[30] D. Urioste, M.B.A. Castro, F.C. Biaggio, H.F. Castro, Quim. Nova 31 (2008) 407-412.

[31] R. Bîrjega, O.D. Pavel, G. Costentin, M. Che, E. Angelescu, Appl. Catal A: Gen. 288 (2005) 185-193. 
[32] M. Herrero, P. Benito, F.M. Labajos, V. Rives, J. Solid State Chem. 180 (2007) $873-884$.

[33] M.K. Ram Reddy, Z.P. Xu, G.Q. Lu, J.C.D. Costa, Ind. Eng. Chem. Res. 45 (2006) 7504-7509.

[34] Z. Li, Y. Song, J. Wang, Q. Liu, P. Yang, M. Zhang, Bull. Mater. Sci. 34 (2011) $183-189$.

[35] L.H. Chagas, S.B.P. Farias, A.A. Leitão, R. Diniz, S.S.X. Chiaro, N.L. Speziali, H.A. Abreu, W.N. Mussel, Quim. Nova 35 (2012) 1112-1117.

[36] J.L. Shumaker, C. Crofcheck, S.A. Tackett, E. Santillan-Jimenez, T. Morgan, Y. Ji, M. Crocker, T.J. Toops, Appl. Catal. B. 82 (2008) 120-130.

[37] V. Rives, Mater. Chem. Phys. 75 (2002) 19-25.

[38] J. Nowicki, J. Lach, M. Organek, E. Sabura, Appl. Catal. A Gen. 524 (2016) 17-24

[39] H.E. Cross, G. Parkes, D.R. Brown, Appl. Catal. A Gen. 429-430 (2012) 24-30.

[40] S.H. Wang, Y. Bin Wang, Y.M. Dai, J.M. Jehng, Appl. Catal. A Gen. 439-440 (2012) 135-141.
[41] F. Guo, Z. Fang, Biodiesel: Feedstocks and Processing Technologies, in: M. Stoytcheva, G. Monteiro (Eds.), In Tech, Rijeka, 2011, pp. 339-358.

[42] D. Gabriëls, W.Y. Hernández, B. Sels, P. Van Der Voort, A. Verberckmoes, Catal. Sci. Technol. 5 (2015) 3876-3902.

[43] J. Das, D. Das, K.M. Parida, J. Colloid Interface Sci. 301 (2006) 569-574

[44] F. Zhang, N. Du, H. Li, J. Liu, W. Hou, Solid State Sci. 32 (2014) 41-47.

[45] J.A. Rivera, G. Fetter, P. Bosch, Microporous Mesoporous Mater. 89 (2006) 306-314.

[46] H. Zhang, X. Wen, Y. Wang, J. Solid State Chem. 180 (2007) 1636-1647.

[47] X. Ma, J. Yu, K. He, N. Wang, Mater. Eng. 292 (2007) 503-510.

[48] Q. Wang, H.H. Tay, Z. Guo, L. Chen, Y. Liu, J. Chang, Z. Zhong, J. Luo, A. Borgna, Appl. Clay Sci. 55 (2012) 18-25. 